\title{
CONDIÇÕES DE TRABALHO E RENORMALIZAÇÕES NAS ATIVIDADES DAS ENFERMEIRAS NA SAÚDE DA FAMÍLIA
}

\author{
WORK CONDITIONS AND RENORMALIZATION OF NURSING ACTIVITIES IN FAMILY HEALTH
}

\author{
Judite Hennemann Bertoncini ${ }^{1}$ \\ Denise Elvira Pires de Pires ${ }^{2}$ \\ Magda Duarte dos Anjos Scherer ${ }^{3}$
}

Resumo Este artigo tem como objetivo analisar a influência das condições de trabalho nas atividades das enfermeiras na Saúde da Família e nas renormalizações que produzem. Trata-se de um estudo qualitativo realizado em um município do sul do Brasil, envolvendo uma amostra intencional de dez enfermeiras. Utilizou-se triangulação metodológica com dados colhidos através de estudo documental, observação e entrevistas de autoconfrontação. Para tratamento e análise dos dados, usaram-se recursos do software Atlas-ti 5 e os fundamentos do materialismo histórico dialético e da ergologia. Os resultados mostraram que condições de trabalho inadequadas, como força de trabalho insuficiente e precariedade dos instrumentos de trabalho, contrariam ou impedem o alcance dos objetivos de promoção da saúde e integralidade prescritos pela Saúde da Família. Conclui-se que, nessas condições, as enfermeiras renormalizam suas atividades com base nos valores de direito à saúde, acesso e integralidade, acarretando sobrecarga de trabalho.

Palavras-chave Saúde da Família; condições de trabalho; papel do profissional de enfermagem; gestão em saúde; ergologia.
Abstract The objective of this article is to analyze the influence of work conditions in Family Health Nursing activities and the renormalizations they produce. It is a qualitative study carried out in a municipality in southern Brazil, involving an intentional sample of ten registered nurses. Methodological triangulation was used with the data collected through documental research, observation, and self-facing interviews. The software Atlas-ti 5 and the foundations of historical dialectic materialism, was used to treat and analyze the data, as well as ergology. The results demonstrate that inadequate work conditions such as insufficient workforce and precariousness in work instruments contradict or impede reaching the objectives of promoting health and integrity, as prescribed by the Family Health norms. We conclude that given these conditions, nurses renormalize their activities based on the values of one's right to health, access to health, and integrality, and become overloaded in their nursing work.

Keywords Family Health; work conditions; role of nursing professional; health management; ergology. 
O trabalho é uma ação antecipada mentalmente, para atender a uma necessidade percebida pelo ser humano, que pode selecionar instrumentos que potencializam a sua ação sobre o objeto de trabalho com vistas a alcançar uma finalidade. Segundo Marx (1988), para conhecer o trabalho é fundamental analisar quem o realiza, a forma como é realizado e em que condições.

Condições de trabalho se referem à força de trabalho, isto é, às especificidades de quem o realiza, à qualificação exigida, à divisão do trabalho, às relações contratuais (modalidade de contrato, jornada de trabalho, benefícios, proteção social). Envolve, também, o ambiente sociotécnico para a realização do trabalho, incluindo instrumentos adequados, em quantidade e qualidade, assim como o conhecimento para operá-los e o espaço físico (Pires, Lorenzetti e Gelbcke, 2010).

A ergologia adota o conceito de atividade para compreender o trabalho. Para Durrive e Schwartz (2008, p. 23) a "actividade é um impulso de vida, de saúde, sem limite predefinido, que sintetiza, cruza e liga tudo o que se representa separadamente (...) (fazer/valores; privado/profissional; imposto/desejado, etc.)". A atividade de trabalho traz, de um lado, as exigências sociais, objetivos impostos, heterodeterminados ('uso de si por outros') e, de outro, a atividade vital como resposta do trabalhador às imposições do meio ('uso de si por si'). Então, trabalhar é gerir debates de normas e suas derivações (Schwartz, 2007a; Brito, 2008; Schwartz e Durrive, 2009) que ultrapassam o meio de trabalho, mas se situam dentro dele (Schwartz, 2006).

Da perspectiva da ergologia, a vida é uma

dramática permanente de negociações entre a obrigação de fazer, na aderência do aqui e agora e um mundo de normas, provisoriamente estabilizadas, antecedentes e anônimas, profundamente ambíguas, criadas em desaderência em relação a esse momento de agir (Schwartz e Durrive, 2009, p. 4).

Para compreender o essencial da atividade, Schwartz (apud Telles e Alvarez, 2004) desenvolveu o conceito de normas antecedentes, que amplia o de trabalho prescrito. As normas antecedentes são as prescrições, tais como: a descrição de uma atribuição profissional, objetivos e metas a serem atingidos; procedimentos predefinidos, normas, instruções e protocolos disponíveis - oralmente ou por escrito -; os meios técnicos disponíveis; a divisão do trabalho estabelecida; os prazos previstos para o alcance das metas e as condições socioeconômicas - como qualificação exigida e salário (Brito, 2008). Além disso, são também as renormalizações que, nos debates de normas e valores, acontecem permanentemente na atividade em função da insuficiência do prescrito para orientar o agir (Schwartz e Durrive, 2009).

A atividade, segundo Schwartz (2007b), é marcada por três características: a transgressão, a mediação e a contradição potencial. É um conceito 
que tenta retomar a unidade do ser humano. Por meio do debate de valores, estabelece mediações entre o individual e o coletivo, entre o micro e o macro da vida social; e nesse processo é produtora de história.

Todo trabalho é uma prática social, por isso é importante considerá-lo em uma realidade histórica e concreta quando se analisa um determinado setor.

O trabalho de enfermagem como parte do processo de trabalho em saúde tem a finalidade de prestar cuidados aos seres humanos e tem, como objeto, o indivíduo, família ou grupo com suas singularidades. Para atuar sobre o objeto, utiliza instrumentos de trabalho (incluindo saberes e condutas), e o produto do trabalho é o cuidado realizado que é produzido e consumido simultaneamente (Pires, 2008, 2010).

Segundo a legislação que regulamenta a profissão (Lei do Exercício Profissional - LEP 7.498/86), a enfermeira, como integrante de equipe de saúde, tem participação na elaboração, planejamento, execução e avaliação de planos e programas de saúde; na prescrição de medicamentos previamente estabelecidos em programas de saúde pública e em rotina aprovada pela instituição; na assistência à gestante, parturiente, puérpera e recémnascido; na educação continuada de pessoal de saúde; na elaboração e operacionalização do sistema de referência e contrarreferência do paciente; nas ações de vigilância epidemiológica; na prevenção e controle de danos físicos ao paciente. Cabe-lhe, ainda, prestar assistência obstétrica e executar parto sem distócia; cooperar no desenvolvimento de tecnologia apropriada à assistência de saúde; participar em bancas examinadoras, em matérias específicas de enfermagem para contratação de enfermeiro, ou técnico e auxiliar de enfermagem (Coren, 2010).

A partir de 2009, o Conselho Federal de Enfermagem (Cofen), através da resolução 358/2009, regulamenta a sistematização da assistência de enfermagem (SAE), que deve ser realizada de modo deliberado e sistemático em todos os ambientes em que ocorre o cuidado profissional de enfermagem. Nos ambientes de cuidado fora do hospital, esta ação corresponde à consulta de enfermagem, que se constitui de cinco etapas: histórico de enfermagem; diagnóstico de enfermagem; planejamento de enfermagem; prescrição de enfermagem e implementação das intervenções; e avaliação de enfermagem. O diagnóstico de enfermagem e a prescrição das ações são atividades privativas da enfermeira (Coren, 2010).

Como prática social, o trabalho das enfermeiras não é orientado somente pela profissão, mas influenciado também pelo contexto econômico, social e político no qual se insere, incluindo a política de saúde em vigor e as normas institucionais.

A Saúde da Família é considerada uma estratégia prioritária para a reorganização da atenção básica, desenvolvendo práticas gerenciais e assistenciais, sob forma de trabalho em equipe multiprofissional que deve atuar na 
perspectiva interdisciplinar, responsabilizando-se pelos problemas de saúde de maior frequência e relevância da população de um território definido. Orienta-se pelos princípios da atenção primária em saúde e do Sistema Único de Saúde (SUS), de universalidade e acessibilidade, coordenação do cuidado, vínculo e continuidade, integralidade, responsabilização, humanização, equidade e participação social (Brasil, 2006).

A equipe mínima preconizada para trabalhar na Estratégia Saúde da Família (ESF) é composta de uma enfermeira, um auxiliar ou técnico de enfermagem, um médico e agentes comunitários de saúde (ACS) suficientes para cobrir $100 \%$ da população cadastrada, no máximo 750 pessoas por ACS (Brasil, 2006).

A Política Nacional da Atenção Básica (Pnab) define as atribuições comuns e específicas de cada membro da equipe, as quais devem ser objeto de normatização do gestor municipal, considerando as prioridades pactuadas com os níveis estadual e federal (Brasil, 2006).

As atribuições específicas da enfermeira previstas pela ESF são: realizar atenção integral aos indivíduos e famílias na Unidade de Saúde da Família (USF), no domicílio e em outros espaços comunitários em todas as fases do desenvolvimento humano; realizar consulta de enfermagem, solicitar exames complementares e prescrever medicações conforme normas técnicas ou protocolos estabelecidos pelo gestor municipal ou federal, observada a legislação profissional; planejar, gerenciar, coordenar e avaliar as ações desenvolvidas pelos ACS; supervisionar, coordenar e realizar atividades de educação permanente dos ACS e da equipe de enfermagem; contribuir e participar das atividades de educação permanente do auxiliar de enfermagem, do auxiliar de consultório dentário (ACD) e do técnico em higiene dental (THD); e participar do gerenciamento dos insumos necessários para o adequado funcionamento da USF (Brasil, 2006).

Além das diretrizes das políticas e das atribuições profissionais, compõem o conjunto das normas antecedentes para o trabalho das enfermeiras as ordens emanadas da hierarquia institucional, os procedimentos e normas técnicas, as diretrizes, os objetivos transmitidos aos trabalhadores relativos aos prazos e produtividade. Estão também aí incluídos as condições dadas para a realização do trabalho, assim como o retrabalho permanente das normas antecedentes e a produção de outras normas na própria atividade.

Como as normas antecedentes são generalizáveis, construídas em 'desaderência' (Schwartz e Durrive, 2009), portanto descontextualizadas, tornam-se insuficientes para enfrentar as variabilidades do meio. A descrição, por exemplo, de princípios e objetivos, bem como a padronização de protocolos e condutas são recursos incompletos para viabilizar a implementação das políticas. Assim, para atingir mudanças no modelo assistencial, é necessário construir um processo de corresponsabilidade entre profissionais, usuários 
e gestores (institucionais) na formulação e nas práticas da atenção à saúde (Scherer, Pires e Schwartz, 2008; Hennington, 2008). Além disso, as prescrições institucionais devem vir acompanhadas das condições concretas para a sua efetivação.

A insuficiência ou a inadequação dos meios de trabalho podem dificultar a realização de atividades ou até mesmo impedi-la. Para Clot (2006), aquilo que foi real(izado) na atividade também pode mostrar muitas alternativas possíveis, propondo o conceito de real da atividade, procurando apreender aquilo que não se fez ou o que se tentou realizar sem êxito, através da análise das atividades suspensas, contrariadas ou impedidas.

Este estudo tem o objetivo de analisar a influência das condições de trabalho nas atividades das enfermeiras na Saúde da Família e as renormalizações que produzem.

\section{Metodologia}

Trata-se de uma pesquisa qualitativa, guiada pelo materialismo histórico dialético e pela ergologia. O materialismo histórico dialético contribui para a compreensão dos fenômenos na sua relação com a totalidade social, entendendo-a como dinâmica e histórica. O estudo sobre a atividade das enfermeiras precisa considerar o contexto político e institucional da USF onde trabalham, incluindo o contexto municipal e da macropolítica de saúde que prescreve normas para o seu fazer e para a organização institucional, assim como as normas da regulação profissional.

A ergologia possibilita a análise de situações complexas de trabalho e tem como categoria central a atividade de trabalho, que é a forma como cada um dialoga com a norma e a renormaliza. Uma situação de trabalho contém as questões macrossociais e, ao realizar seu trabalho de determinada maneira, o indivíduo toma posição nestes debates da sociedade, reconstituindo tais questões no seu ambiente micro (Duc, Duraffourg e Durrive, 2007).

A análise da atividade tem o propósito de confrontar os saberes necessários para compreender o trabalho, com a experiência de quem trabalha em uma situação concreta, provocando o debate de normas e valores. Cria, assim, lugares para a emergência desses debates, que podem fundar políticas coletivas (saúde) no nível micro, em relação dialética com o nível político mais geral (Schwartz, 2007b).

A pesquisa foi realizada em um município do sul do Brasil, com amostra constituída por dez enfermeiras que atenderam aos seguintes critérios de inclusão: trabalhar em USF em diferentes regiões do município, atuar há pelo menos um ano na ESF e consentir em participar da pesquisa. O tamanho da amostra foi considerado suficiente para a compreensão, em profundidade, 
do fenômeno, pois, tanto na observação quanto na entrevista, os dados mostraram-se saturados (Minayo et al., 2005).

Os profissionais aderiram voluntariamente à pesquisa e assinaram o Termo de Consentimento Livre e Esclarecido (TCLE), após responder às dúvidas em contato individual. Os dados foram coletados de março a agosto de 2010, utilizando-se a triangulação metodológica (Denzin, 1987), através de estudo documental, observação sistemática e entrevista de autoconfrontação (Vieira, 2004). Analisaram-se documentos referentes à Política Nacional da Atenção Básica do Ministério da Saúde, que tratam das atribuições dos profissionais na ESF; documentos de normatização para a ESF, normas e protocolos assistenciais para a enfermagem, no nível municipal; a LEP 7.498 de 25/6/1986, o decreto 94.406 de 8/6/1987 e a resolução Cofen 358 de 15/10/2009.

A pesquisadora principal acompanhou as atividades realizadas pelas enfermeiras durante diferentes dias da semana, nos períodos da manhã e da tarde, conforme agenda de cada unidade, e registrou as observações em diário de campo, perfazendo uma média de 16 horas por enfermeira. Os registros foram submetidos à análise de cada uma delas, sendo utilizados como base para entrevista, em sessão específica para propiciar a autoconfrontação da enfermeira com a prática observada. Na entrevista foi solicitado que ela comentasse e explicasse suas escolhas em vários momentos de sua atividade (Vieira, 2004). As entrevistas foram gravadas e, posteriomente, transcritas e enviadas ao sujeito da pesquisa para validação, obtendo-se vinte documentos para análise (dez de observação e dez de entrevistas).

Na organização e tratamento dos dados, utilizou-se um software para análise de dados qualitativos, o Atlas-ti 5 (Qualitative Research and Solutions - Non-numeric Unstructured Data - Index, Searching and Theorizing), que permite o armazenamento, codificação e integração de grande quantidade de dados complexos (Esteban, 2006). Os documentos da observação e entrevistas foram inseridos no Atlas-ti em vinte arquivos individuais denominados "documentos primários" e numerados de 1 a 20, conformando uma unidade hermenêutica. Em cada documento os dados foram decompostos em 'códigos' e selecionados os fragmentos (falas ou notas de observação) do texto que ilustram o referido código. Os códigos foram construídos a partir do referencial teórico adotado - especialmente a concepção de atividade (trabalho prescrito/normas antecedentes/condições de trabalho e renormalizações), com a identificação de coerências e contradições nas falas e práticas das enfermeiras - e 'memorandos' com interpretação das pesquisadoras. Os códigos que apresentavam um mesmo sentido foram agrupados e formaram 'famílias', articuladas, após exaustiva leitura e interpretação, em três categorias de análise: força de trabalho - a composição das equipes e a (re)composição do trabalho -, relações contratuais e instrumentos de trabalho - déficits influenciando a gestão da atividade. 


\section{Resultados e discussão}

\section{Força de trabalho: a composição das equipes e a (re)composição do trabalho}

De acordo com as observações efetuadas e o relato dos sujeitos, a força de trabalho, em quantidade e qualidade, mostrou-se insuficiente para a realização das atividades atribuídas às enfermeiras na Saúde da Família.

No município estudado, a equipe da ESF era composta de: uma enfermeira, dois auxiliares de enfermagem, um médico, um auxiliar administrativo, um auxiliar de serviços gerais e cinco ACS. Em algumas unidades do município havia cirurgião-dentista, técnico em higiene dental e acadêmicos de enfermagem, medicina, psicologia e nutrição (Blumenau, 2010).

Em relação à composição das equipes, o município apresentou uma estabilidade dos profissionais de enfermagem, e o número de auxiliares por equipe era maior que o prescrito pelo gestor federal para a equipe mínima (Brasil, 2006). No entanto, em 50\% das equipes faltava o ACS, e duas equipes não contavam com nenhum deles. Em mais de $50 \%$ das equipes não havia auxiliar administrativo, e 30\% das equipes estavam sem médico.

Para gerir a falta de médico, as enfermeiras enfrentavam uma dramática na qual estavam envolvidas as prescrições da política nacional e do gestor municipal, suas crenças e valores e as condições concretas de trabalho de que dispõem. As situações descritas, a seguir, ilustram as escolhas na gestão do déficit na composição das equipes.

Em uma USF que contava com duas equipes, ambas sem médico (por dificuldades de contratação), um profissional que não era da ESF vinha à unidade duas manhãs por semana para realizar as consultas dos usuários adscritos às duas equipes.

Os dias que o médico não vem, a enfermeira atende todos os usuários que comparecem à unidade, e encaminha para o ambulatório geral (AG) de referência, que oferece quatro vagas para consulta médica. $\mathrm{O}$ atendimento é realizado pela enfermeira como parte do acolhimento, para isso ela usa o prontuário família, começando com o histórico e exame físico, a seguir avalia a situação e faz as intervenções e encaminhamentos que julga necessários. Não solicita exames complementares nem prescreve medicamentos. Após avaliar o que o usuário necessitava, depois de preencher as quatro vagas, a enfermeira telefonou para o AG e para as outras USF, começando pelas mais próximas, solicitando vaga para consulta médica, encaminhando o usuário com o formulário de referência preenchido e assinado (nota de observação).

Quando confrontada a esta situação na entrevista, a enfermeira comentou: 
Depois que o secretário proibiu, eu posso até saber, mas não prescrevo nada. A minha colega prescreve, mas eu acho que ela está se arriscando. Pelo menos os médicos aceitam os meus encaminhamentos porque me conhecem, alguns não gostam, mas esses são tranquilos (Enfermeira 9).

Em outra equipe o médico estava há três meses de licença para tratamento de saúde e não foi substituído. Nesse caso, para realizar o acompanhamento dos usuários em condições crônicas (hipertensão, diabetes, sofrimento psíquico) e/ou que dependem de medicação de uso contínuo, a enfermeira atendia e, de acordo com protocolos do Ministério da Saúde, solicitava os exames complementares e fornecia as receitas conforme o que constava prescrito anteriormente (pelo médico da sua equipe) no prontuário. Então, levava as receitas e requisições preenchidas, com os respectivos prontuários de cada usuário, para o médico da USF vizinha ou para o diretor de saúde (gestor de todas as USF) carimbar e assinar.

A prescrição de medicamentos e solicitação de qualquer tipo de exame complementar, que era praticada no município até 2005, passou a ser proibida pelos gestores municipais, contradizendo a legislação profissional e o Ministério da Saúde que preveem esta atividade para a enfermeira. Apesar dos impedimentos, observou-se que a profissional não se resignava e, na singularidade da sua experiência, encontrava alternativas para que os usuários mantivessem o tratamento. No debate de normas e valores, a escolha parece ter sido orientada pelo valor de garantia de acesso aos serviços e cuidados de saúde.

A alta rotatividade do profissional médico é um problema existente em vários municípios brasileiros e considerado uma fragilidade na consolidação da ESF (Bertoncini, 2000; Nascimento e Nascimento, 2005; Campos e Malik, 2008).

\section{Déficit de auxiliar administrativo e ACS}

Para suprir a falta dos auxiliares administrativos verificada na metade das equipes estudadas, assim como para atender a um conjunto de normas antecedentes, as enfermeiras utilizavam diversas estratégias. "Para que a unidade não pare de funcionar, uma solução foi designar o ACS para trabalhar dentro da USF substituindo o auxiliar administrativo, o que impedia o acompanhamento dos usuários pelo ACS" (nota de observação).

Esta renormalização acarretava prejuízo em outra ação prescrita, a de que o ACS realize ações, como o acompanhamento dos marcadores de saúde e a vigilância em saúde, pelas quais a enfermeira é responsável, segundo o gestor local: "Eventos como hospitalização vão ser conhecidos somente quando vem alguém da família na unidade" (E 9). 
Algumas enfermeiras assumiam tarefas administrativas, diminuindo o tempo que teriam para realizar atividades específicas da profissão. Nesse caso, ficavam horas ao telefone fazendo busca ativa devido à falta do ACS.

Sem o agente de saúde, a gente não tem pernas para alcançar tudo, nós priorizamos esses, os idosos que são hipertensos ou diabéticos, então esses a gente liga, mas é demais, a gente não consegue ligar para todos (E 2).

O nosso maior problema é que, com a falta do agente de saúde, a gente acaba tendo que usar o nosso tempo muito no telefone. E levantamos os telefones de todos e começamos a ligar, mas são muitos, vão ser duzentas e poucas ligações, não é fácil de fazer (E 7).

Os relatórios do Siab [Sistema de Informação da Atenção Básica] são preenchidos somente da microárea 1 , e os outros vão em branco porque só tem um agente de saúde. O cadastro está desatualizado faz tempo (E 3).

A falta do ACS nas equipes trouxe prejuízo em muitas atividades prescritas pela ESF, entre elas: cadastrar a população da área de abrangência; realizar diagnóstico situacional, planejamento e programação; realizar ações dirigidas aos problemas de saúde de forma pactuada com a comunidade; cuidar dos indivíduos e das famílias ao longo do tempo; atuar com foco na família e comunidade; desenvolver parcerias com organizações sociais; ser um espaço de construção de cidadania (Brasil, 2006).

Diante da impossibilidade de aplicar as prescrições da maneira como estão postas, os profissionais se dão normas e optam por atender ao que julgam mais urgente, priorizando, por exemplo, a atenção a determinados grupos.

\section{Divisão do trabalho na equipe de enfermagem e de saúde}

Outros exemplos da influência das condições de trabalho na atividade das enfermeiras, em especial do déficit na composição das equipes, podem ser ilustrados com o caso de uma enfermeira que delegou o trabalho com o grupo de gestantes aos estagiários de nutrição e deixou o grupo de puericultura sob a responsabilidade da auxiliar de enfermagem, assim como restringiu as visitas domiciliares apenas para casos estritamente necessários. Justificou a sua decisão pela falta de tempo para desenvolver atividades com grupos ou fora do espaço físico da USF.

Em outra equipe, no período em que estava sem o auxiliar administrativo, foi realizado um revezamento nas tarefas administrativas entre a enfermeira, auxiliares de enfermagem e médico. “Enquanto estamos sem o auxiliar 
administrativo é assim, todas nós, até o médico, atendemos na recepção, atendemos telefone, fazemos agendamento, marcação" (E 5).

Essas situações caracterizam desvio de função de vários profissionais, da enfermeira, dos auxiliares de enfermagem, do ACS e do médico, e evidenciam o trabalho concreto em função da necessidade de eficácia na atenção à saúde.

Em algumas situações, o trabalho das enfermeiras e dos auxiliares de enfermagem ocorreu sem diferenciação de atribuições e em outras correspondeu ao prescrito na legislação profissional. O acolhimento bem como a decisão dos encaminhamentos e intervenções necessárias ao usuário são atribuições da enfermeira. No acompanhamento dos portadores de hipertensão ou diabetes e das gestantes e das crianças, cada profissional realiza parcelas diferentes do trabalho, o médico, o auxiliar e a enfermeira e o ACS.

Significa, como afirmam Schwartz e Durrive (2009), que nem todas as normas têm o mesmo status, elas sofrem hierarquizações e são cristalizadas na prática segundo as escolhas dos coletivos de trabalho.

\section{Relações contratuais}

Enfermeiras, auxiliares de enfermagem e médicos são concursados em regime estatutário. Alguns médicos têm contrato temporário devido à alta rotatividade deste tipo de profissional. Alguns ACS são concursados e outros têm um contrato temporário por um período de seis meses. Os auxiliares administrativos podem ser concursados, mas uma parcela deles é formada de estagiários, e as auxiliares de serviços gerais são terceirizadas.

No município em estudo, cabe à enfermeira coordenar a equipe e é sua atribuição providenciar a substituição dos servidores que faltam, dos que estejam em licença para tratamento de saúde, dos que entram em férias, ou, sempre que necessário, para garantir a continuidade da oferta dos serviços de saúde à população (Blumenau, 2010). Essa situação aumenta o trabalho da enfermeira que, de seis em seis meses, tem de fazer a solicitação da contratação, participar da seleção, treinar e avaliar os novos ACS e auxiliares administrativos.

O estudo de Kawata e colaboradores (2009) também identificou que as enfermeiras desenvolvem o planejamento de ações para a organização do cuidado juntamente com o exercício da coordenação da Unidade Básica, o que resulta em sobrecarga de trabalho.

No que se refere à diversidade das formas de inserção dos trabalhadores nas equipes, até mesmo daqueles com contratos precários, a mesma situação foi encontrada em outros estudos e identificada como uma fragilidade e um 
desafio a ser enfrentado na gestão do trabalho no SUS (Pierantoni, Varella e França, 2006).

Sanches e colaboradores (2010), em estudo realizado em Santa Catarina, analisando o compromisso dos profissionais da ESF, referem que o descomprometimento com o trabalho e com a organização esteve associado à precarização do trabalho, já que $82 \%$ desses profissionais tinham vínculo temporário.

O estudo de Scherer (2006, p. 206), realizado com equipes de Saúde da Família no sul do Brasil, destaca a ideia de que a constituição da equipe mínima é limitada para responder à complexidade do processo saúdedoença, e que "qualquer equipe prescrita é limitada, porque os coletivos se recompõem em função da necessidade".

Kawata e colaboradores (2009) consideram que a equipe prescrita pelo Ministério da Saúde apresenta uma possibilidade teórica de recomposição do trabalho coletivo. Referem, ainda, que a definição de um rol de atividades não assegura a recomposição do trabalho individual e autônomo dos trabalhadores para dar conta da multiprofissionalidade. Isto pressupõe que as prescrições são recursos incompletos, que há defasagem entre o que foi antecipado pela prescrição e as situações encontradas no cotidiano de trabalho (Schwartz, 2007a; Brito, 2008).

Para fazer frente aos déficits na composição das equipes e, ao mesmo tempo, considerar as prescrições da política de saúde - as profissionais e as pessoais -, as enfermeiras tomam decisões que muitas vezes implicam suspender atividades, contrariadas e impedidas pelas condições de trabalho.

As enfermeiras suspendem, por exemplo, o acompanhamento das hospitalizações; a captação das gestantes no primeiro trimestre de gravidez; a busca ativa das crianças com atraso vacinal, dos portadores de hipertensão e diabetes faltosos, entre outros. Delegam ao ACS a substituição do auxiliar administrativo de forma contrariada, porque isto impede a atualização do cadastro das famílias, o que, por sua vez, dificulta o planejamento e a avaliação das ações, bem como o acompanhamento das metas do Pacto de Indicadores: "Eu sei que eles [os ACS] não deveriam trabalhar aqui dentro da unidade, mas é o único jeito, se sobra um tempinho eles fazem as visitas" (E 10).

Uma das enfermeiras demonstrou sua insatisfação e parece justificar a si mesma porque leva as requisições de exames e receitas de medicamentos dos usuários que fazem tratamento de uso contínuo para o médico assinar.

Eu já pensei se está certo fazer isto, parece assistencialismo, mas como é que eu vou deixar todos esses pacientes sem tratamento? Nunca vou conseguir encaminhar todos para consulta médica! Mas eu levo o prontuário para ele [o médico] ver que eu não estou prescrevendo nada de novo (E 5). 


\section{Instrumentos de trabalho: déficits influenciando a gestão da atividade}

Os instrumentos de trabalho não se reduzem aos equipamentos e máquinas, mas incluem o conhecimento para operá-los (Pires, Lorenzetti e Gelbcke, 2010). Os profissionais têm formação específica, mas necessitam incorporar as mudanças que ocorrem no processo de trabalho, no perfil demográfico e epidemiológico, nas novas tecnologias de procedimentos clínicos, assim como as advindas do uso intensivo das tecnologias de informação e comunicação nos serviços.

Nesse município, as equipes da ESF têm capacitação permanente sobre temas relacionados às práticas profissionais requeridas para a implementação das diretrizes da Pnab, mas esta responsabilidade da Secretaria Municipal de Saúde é dividida com a enfermeira. Entre as funções da coordenadora da equipe (atividade que no município estudado foi destinada às enfermeiras), consta realizar reuniões com a equipe e mantê-la atualizada quanto aos conhecimentos técnicos e políticas de saúde. No entanto, as dificuldades apresentadas pela equipe no que diz respeito à incorporação de inovação tecnológicas ultrapassam as possibilidades de atuação da enfermeira, gerando o que Schwartz e colaboradores (2007) chamam de prescrições infinitas. “Em uma USF, a atendente de enfermagem está se aposentando e não faz atividades de enfermagem, faz atividades do auxiliar administrativo, com restrições, por dificuldades com as tecnologias de informação" (nota de observação).

\section{Déficit de equipamentos e instrumentos de trabalho}

É atribuição da enfermeira realizar assistência integral no domicílio e em outros espaços comunitários, bem como ações de vigilância e promoção da saúde fora da unidade (Brasil, 2006). A Secretaria Municipal de Saúde disponibiliza um carro durante um período da semana para cada equipe fazer visita domiciliar. As enfermeiras usam algumas estratégias para realizar as atividades fora da unidade. Um exemplo são as ações direcionadas ao aumento da cobertura vacinal. "A fim de aumentar a cobertura vacinal, as enfermeiras estendem esta atividade além do horário de funcionamento da unidade, até as 20 horas ou no sábado" (nota de observação).

Algumas USF não têm sala de vacina por falta de espaço físico. Em uma dessas, a enfermeira programou a oferta de todas as vacinas aproveitando o dia da campanha. Dois dias antes da data fixada, ela recebeu aviso da supervisora por telefone, suspendendo a vacinação que tinha sido marcada para o sábado, alegando não ter carro disponível para levar as vacinas até a unidade onde seriam aplicadas. Assim, os usuários teriam de se deslocar até a unidade mais próxima para receber a vacina. A enfermeira comunicou que 
esta medida dificultaria o acesso da população às vacinas, mantendo os baixos índices de cobertura, e que não poderia suspender o serviço, pois já tinham avisado toda a comunidade. "Eu não podia fazer isso com a comunidade, eles já estão todos avisados, e depois (...) a Secretaria vem reclamar que a nossa cobertura está baixa" (E 10).

Para gerir a atividade, vacinar e aumentar a cobertura vacinal, considerando os déficits de condições de trabalho (neste caso, insuficiência de instrumentos) e os valores de promoção da saúde/proteção específica e de integralidade, a enfermeira decidiu buscar as vacinas e o material necessário com o carro próprio, realizando a atividade programada.

David e colaboradores (2009), em estudo sobre o impacto da organização do trabalho de enfermeiros, técnicos e auxiliares de enfermagem na atenção básica, identificaram sobrecarga, precarização do trabalho e baixa disponibilidade de equipamentos e insumos para adequada prática profissional. Além disso, constaram que precárias condições de trabalho trazem problemas para os trabalhadores, como interrupções no trabalho, exposição a risco (para o profissional e o usuário), ansiedade e trabalho incompleto.

\section{Considerações finais}

Este estudo evidencia fragilidades da Pnab e põe em debate a sua capacidade de se efetivar como estratégia estruturante do sistema de saúde.

A análise da atividade das enfermeiras na ESF fez emergir o abismo existente entre as prescrições institucionais das políticas de saúde e as condições concretas de trabalho disponibilizados para a sua realização. A decomposição do trabalho é marcada, nesse município, pela insuficiência da força de trabalho, em quantidade e qualidade e, pela falta ou inadequação dos instrumentos de trabalho.

As normas antecedentes são infinitas quanto aos objetivos a serem alcançados, tais como acesso universal e integralidade; orientam o agir, mas são renormalizadas pelas enfermeiras quando aplicadas ao seu contexto específico, como resposta à necessidade de ser eficaz na atenção à saúde da população sob sua responsabilidade. As condições de trabalho precárias parecem intensificar esse processo de normalização e renormalização que é inerente à vida, exigindo determinação e iniciativa dos profissionais para enfrentar as infidelidades do meio.

As profissionais parecem dominar suficientemente as tecnologias materiais e não materiais para resolver a maioria dos problemas que acometem a população pela qual são responsáveis. Porém, ao se depararem com as variabilidades impostas pelas condições de trabalho, as enfermeiras renormalizam com base em valores de direito à saúde e integralidade, mas com forte 
orientação para atender às demandas do gestor municipal de produtividade, de "não deixar o serviço parar".

A deterioração das condições de trabalho - falta do médico, do ACS e do auxiliar administrativo e as modalidades contratuais - produz consequências nefastas, dificultando o desenvolvimento de atividades em direção à produção da saúde/ integralidade. Para as enfermeiras, a precarização do trabalho acarreta sobrecarga física e psíquica, desvio de função e pouca possibilidade de desenvolver o trabalho seguindo os parâmetros profissionais, como, por exemplo, deixando de usar a metodologia da Sistematização da Assistência de Enfermagem.

O impedimento da realização de determinadas atividades pelo gestor municipal, contrariando a legislação profissional e as orientações do Ministério da Saúde, colocam as enfermeiras no confronto entre agir, de um lado, em função das necessidades de saúde da população, transgredindo ou inventando, e, de outro, das imposições da norma que limitam sua atuação.

As enfermeiras demonstram a necessidade de realizar gestões complexas de suas atividades, negociando valores e objetivos com os profissionais médicos e gestores municipais, com vistas à organização do trabalho e a se aproximarem mais do prescrito na Pnab.

\section{Nota do Editor}

Este artigo foi produto da tese de doutorado em Enfermagem intitulada Entre o prescrito e o real: renormalizações possiveis no trabalho das enfermeiras na saúde da família, de Judite Hennemann Bertoncini, apresentada, em 15 de fevereiro de 2011, na Faculdade de Enfermagem da Universidade Federal de Santa Catarina (UFSC). A primeira autora realizou a pesquisa de campo e participou de todas as etapas de produção do artigo. A segunda autora participou na condição de orientadora. A terceira autora colaborou na análise dos dados e na revisão do artigo. 


\section{Notas}

1 Professora do Departamento de Enfermagem da Universidade Regional de Blumenau, Blumenau, Santa Catarina, Brasil. Doutoranda em Enfermagem pela Universidade Federal de Santa Catarina (UFSC). <juditeb@furb.br> Correspondência: Rua Ernest Auerbach, n. 181, Itoupava Seca, CEP 89035-560, Blumenau, Santa Catarina, Brasil.

2 Professora do Departamento de Enfermagem da Universidade Federal de Santa Catarina (UFSC), Florianópolis, Santa Catarina, Brasil. Doutora em Ciências Sociais pela Universidade Estadual de Campinas (Unicamp), com pós-doutorado pela University of Amsterdam. <piresdp@yahoo.com>

3 Professora adjunta do Departamento de Saúde Coletiva da Universidade de Brasília (UnB), Brasília, Brasil. Doutora em Enfermagem pela Universidade Federal de Santa Catarina (UFSC).<magscherer@hotmail.com>

\section{Referências}

ATLAS-TI. The qualitative data analysis software. Disponível em: <www.atlasti.com>. Acesso em: 13 out. 2008.

BERTONCINI, Judite Hennemann. Da intenção ao gesto: análise da implantação do Programa Saúde da Família em Blumenau. Dissertação (Mestrado em Saúde Pública), Florianópolis: Programa de Pós-Graduação em Enfermagem, Universidade Federal de Santa Catarina, 2000.

BLUMENAU. Secretaria Municipal de Saúde. Coordenação da Atenção Básica. Relação das unidades da rede municipal de saúde. Blumenau: SMS, 2010.

BRASIL. Ministério da Saúde. Secretaria de Atenção à Saúde. Departamento da Atenção Básica. Politica Nacional da Atenção Básica. Brasília: Ministério da Saúde, 2006. (Pactos pela Saúde, 4).

BRITO, Jussara Cruz de. Trabalho real. In: PEREIRA, Isabel Brasil; LIMA, Júlio César França (Orgs.). Dicionário da educação profissional em saúde. 2. ed. rev. ampl. Rio de
Janeiro: Escola Politécnica de Saúde Joaquim Venâncio, 2008. p. 453-459.

CAMPOS, Cláudia Valentina de Arruda; MALIK, Ana Maria. Satisfação no trabalho e rotatividade dos médicos do Programa de Saúde da Família. Revista de Administração Pública, Rio de Janeiro, v. 42, n. 2, p. 347368,2008

CLOT, Yves. A função psicológica do trabalho. Petrópolis: Vozes, 2006.

COREN (Conselho Regional de Enfermagem). Legislação e resoluções do exercício profissional. In: PIRES, Denise Elvira Pires de et al. (Orgs). Consolidação da legislação e ética profissional. Florianópolis: Conselho Regional de Enfermagem-SC: Quorum Comunicação, 2010. p. 51-96.

DAVID, Helena Maria Scherlowski Leal et al. Organização do trabalho de enfermagem na atenção básica: uma questão para a saúde do trabalhador. Texto \& Contexto Enfermagem, Florianópolis, v. 18, n. 2, p. 206-214, abr./jun. 2009. 
DENZIN, Norman K.; HAGUETTE, Teresa Maria Frota. Metodologias qualitativas na sociologia. Petrópolis: Vozes, 1987.

DUC, Marcelle; DURAFFOURG, Jacques; DURRIVE, Louis. O trabalho e o ponto de vista da atividade. In: SCHWATZ, Yves; DURRIVE, Louis. (Orgs.). Trabalho e ergologia: conversas sobre a atividade humana. Tradução de Jussara Brito et al. Niterói: EdUFF, 2007. p. 47-82.

DURRIVE, Louis; SCHWARTZ, Yves. Glossário da ergologia. Laboreal, Rio de Janeiro, v. 4, n. 1, p. 23-28, jun. 2008.

ESTEBAN, Maria Paz Sandín. Introduccion al programa de análisis de datos cualitativos Atlas-ti 5.O. Barcelona: Facultad de Pedagogía, Universidad de Barcelona, 2006.

HENNINGTON, Élida Azevedo. Gestão dos processos de trabalho e humanização em saúde: reflexões a partir da ergologia. Revista de Saúde Pública, São Paulo, v. 42, n.3, p. 555-561, jun. 2008.

KAWATA, Lauren Suemi et al. O trabalho cotidiano da enfermeira na saúde da família: utilização de ferramentas da gestão. Texto \& Contexto Enfermagem, Florianópolis, v. 18, n. 2, p. 313-320, abr./jun., 2009.

MARX, Karl. O capital: crítica da economia política. Livro 1. Rio de Janeiro: Bertrand Brasil, 1988. v. 1.

MINAYO, Maria Cecília de Souza et al. Métodos, técnicas e relações em triangulação. In: MINAYO, Maria Cecília de Souza et al. (Orgs). Avaliação por triangulação de métodos: abordagens de programas sociais. Rio de Janeiro: Editora Fiocruz, 2005. p. 71-103.

NASCIMENTO, Maristella Santos; NASCIMENTO, Maria Angela Alves do. A prática da enfermeira no Programa de Saúde da Família: a interface da vigilância da saúde versus as ações programáticas em saúde. Ciência \& Saúde Coletiva, Rio de Janeiro, v. 10, n. 2, p. 333-345, abr./jun. 2005.
PIERANTONI, Célia Regina; VARELLA, Thereza Christina; FRANÇA, Tânia. Recursos humanos e gestão do trabalho em saúde: da teoria para a prática. Cadernos de Recursos Humanos em Saúde, Rio de Janeiro, v. 3, n. 1, p. 27-38. 2006.

PIRES, Denise Elvira Pires de. A enfermagem enquanto disciplina, trabalho e profissão. Revista Brasileira de Enfermagem, Brasília, v. 62, n. 5, p. 739-744, 2008.

Reestruturação produtiva e trabalho em saúde no Brasil. São Paulo: Annablume, 2010.

PIRES, Denise Elvira Pires de; LORENZETTI, Jorge; GELBCKE, Francine Lima. Enfermagem: condições de trabalho para um fazer responsável. In: CONGRESSO BRASILEIRO DE ENFERMAGEM, 62., 2010, Anais... Florianópolis: CBEn.

SANCHES, Elizabeth Navas et al. Organização e trabalho: padrões de comprometimento dos profissionais que atuam na estratégia saúde da família. Revista Eletrônica de Enfermagem, Goiânia, v. 12, n. 2, p. 294-300, 2010.

SCHERER, Magda Duarte dos Anjos. O trabalho na Equipe de Saúde da Família: possibilidades de construção da interdisciplinaridade. Tese (Doutorado em Enfermagem), Florianópolis: Programa de Pós-Graduação em Enfermagem, Universidade Federal de Santa Catarina, 2006.

SCHERER, Magda Duarte dos Anjos; PIRES, Denise Elvira Pires de; SCHWARTZ, Yves. Trabalho coletivo: um desafio para a gestão em saúde. Revista de Saúde Pública, São Paulo, v. 43, n. 4, p. 721-725, 2009.

SCHWARTZ, Yves. Entrevista: Yves Schwartz. Trabalho, Educação e Saúde, v. 4, n. 2, p. 457466. 2006

Un bref aperçu de l'histoire culturelle du concept d'activité. Activités, v. 4, n. 2, p. 122-133, 2007a. Disponível em: <www. activites.org/v4n2/v4n2.pdf $>$. Acesso em: 12 jan. 2011. 
Reflexão em torno de um exemplo de trabalho operário. In: ; DURRIVE, Louis (Orgs.). Trabalho e ergologia: conversas sobre a atividade humana. Tradução de Jussara Brito et al. Niterói: EdUFF, 2007b. p. 37-46.

SCHWARTZ, Yves et al. O trabalho se modifica. In: SCHWARTZ, Yves; DURRIVE, Louis. (Orgs.). Trabalho e ergologia: conversas sobre a atividade humana. Tradução de Jussara Brito et al. Niterói: EdUFF, 2007. p. 23-47.

SCHWARTZ, Yves; DURRIVE, Louis. L'activité en dialogues: entretiens sur l'activité humaine (II). Toulouse: Octarès Éditions, 2009.
TELLES, Ana Luiza; ALVAREZ, Denise. Interfaces ergonomia-ergologia: uma discussão sobre trabalho prescrito e normas antecedentes. In: FIGUEIREDO, Marcelo et al. (Orgs.). Labirintos do trabalho: interrogações e olhares sobre o trabalho vivo. Rio de Janeiro: DP\&A, 2004. p. 63-90.

VIEIRA, Marco Antônio. Autoconfrontação e análise da atividade. In: FIGUEIREDO, Marcelo et al. (Orgs.). Labirintos do trabalho: interrogações e olhares sobre o trabalho vivo. Rio de Janeiro: DP\&A, 2004. p. 214-237.

Recebido em 11/02/2011

Aprovado em 27/02/2011 